\title{
STEM STRAIGHTNESS AS AFFECTED BY ROW-THINNING A RED PINE PLANTATION
}

\author{
BY W. M. STIELL ${ }^{1}$
}

\section{ABSTRACT}

A 20-year-old red pine plantation, spaced $6 \times 6$ feet, was thinned by removing every third row. Five years later the residual trees showed very little stem curvature, and it was concluded that row-thinning similar plantations would not result in sufficient sweep to degrade the value of the trees.

The most feasible way to make a first thinning in a plantation of uniform spacing and relatively high survival is, usually, to remove whole rows at intervals throughout the stand. One criticism of this method has been that the trees in the residual rows would grow or lean towards the side on which they were released, developing sweep.

Büsgen and Münch (1929) describe two ways in which straightness of stem can be influenced by increased light from one side. The leading shoot of a phototropic species can bend towards the direction from which the strongest light comes; or thicker and longer branches can develop on the side of the tree receiving the most light, with the additional weight of the crown on that side causing a purely mechanical bending of the stem. A phototropic response, therefore, would affect only the part of the stem formed after release on one side; on the other hand, bending due to the mechanical pressure of an unbalanced crown could occur much lower down the stem.

To test the theory of curvature developing as a result of row thinning, an investigation was made in a 20 -year-old plantation of red pine (Pinus resinosa Ait.) at the Petawawa Forest Experiment Station, near Pembroke, Ontario. The plantation, established at a spacing of about $6 \times 6$ feet, had been thinned in 1953 by removing every third row. Each residual row, then, had a row 6 feet away on one side, and one 12 feet away on the other side.

In 1958, 20 trees were selected at random and measurements were made from each of these to the tree most nearly opposite it in the row 12 feet away. For each pair of trees the measurements were of horizontal distance, at ground level and from the mid-points of the 1958,1953,1948, 1943, and 1938 internodes of the shorter tree. These measurements were taken between stem centres, not between the nearest sides of the stems. Height to each measurement point was recorded also. None of the trees in this study was situated next to a gap in either its own row or in the adjacent row. Observations were taken from a portable aluminum tower, by means of a 14-foot graduated pole with attached level.

It was assumed that a change in distance between stems from one date to the next would indicate curvature of the stems. The significance between distances at any two dates was determined by t-test, using the procedure applicable to paired individuals (Snedecor, 1946).

\footnotetext{
${ }^{2}$ Forestry Officer, Forestry Branch, Department of Northern Affairs and National Resources, Ottawa.
} 
TABLE 1

\begin{tabular}{lcccc}
\hline & $\begin{array}{c}\text { Height } \\
\text { (Feet) }\end{array}$ & $\begin{array}{c}\text { Average Horizontal } \\
\text { Distance Between } \\
\text { Stems (Inches) }\end{array}$ & $\begin{array}{c}\text { Deviation from } \\
\text { Distance at } \\
\text { Ground Level }\end{array}$ & $\begin{array}{c}\text { Signtf- } \\
\text { icancet }\end{array}$ \\
\hline Ground level & $\mathbf{0}$ & 143.1 & & \\
1938 & 1.7 & 142.9 & -0.2 & NS \\
1943 & 6.5 & 142.2 & -0.9 & NS \\
1948 & 14.3 & 141.3 & -1.8 & HS \\
1953 & 23.5 & 139.8 & -3.3 & HS \\
1958 & 31.8 & 139.7 & -3.4 & HS \\
\hline
\end{tabular}

'NS-not significant at $5 \%$ level; HS-significant at $1 \%$ level.

Table 1 indicates that distance between stems in adjoining rows decreases with height. Trees are, therefore, closest together at the top where the average distance between 1958 leaders is 3.4 inches less than the distance between stems at ground level. This difference, which is significant at the one per cent level, is evidence of curvature somewhere along the stem. However, since the average difference involves two trees, leaning towards each other, the actual deflection from the vertical per tree is only half this value, or 1.7 inches in 31.8 feet.

The nature, or shape, of the sweep is defined in Table 2, where differences are shown between successive measurement points, and in Figure 1 where deflection values are plotted per tree.

TABLE 2

\begin{tabular}{lcccc}
\hline & $\begin{array}{c}\text { Length } \\
\text { (Feet) }\end{array}$ & $\begin{array}{c}\text { Difference in } \\
\text { Distance Between } \\
\text { Stems (Inches) }\end{array}$ & Significance & $\begin{array}{c}\text { Feet of } \\
\text { stem Per } \\
\text { Inch } \\
\text { Deviation }\end{array}$ \\
\hline 1938 -ground & 1.7 & -0.2 & NS & 17.0 \\
$1943-1938$ & 4.8 & -0.7 & NS & 13.7 \\
$1948-1943$ & 7.8 & -0.9 & NS & 17.3 \\
$1953-1948$ & 9.2 & -1.5 & HS & 12.3 \\
$1958-1953$ & 8.3 & -0.1 & NS & 166.0 \\
\hline
\end{tabular}

The change in distance between stems from 1953 to 1958 , that is, in the period after thinning, is very slight, averaging 0.1 inch per pair of trees, or a deflection of only 0.05 inch in 8.3 feet per tree. This value is not significant at the 5 per cent level. It appears, therefore, that there was no appreciable phototropic response to row thinning.

Most (97 per cent) of the total deflection occurred below 1953, and presumably was caused by the weight of additional crown developed on the released side of the tree. This deflection is fairly uniform per unit of stem length, suggesting that the point of bending is at or near ground level. The stem, although leaning, is therefore relatively straight up to 1953. The reduced deffection above 1953 results in sharper curvature, so that the most crooked part of the stem is that section above 1948. The length of this section is 17.5 feet, and the deviation from the straight caused by the crook at 1953 (i.e. the perpendicular distance from the broken line in Figure 1 to the point 1953) 
is 0.33 inches. This is equivalent to 1 inch of deviation in 53 feet of stem length, a negligible amount. With the crowns approaching closure across the gaps of the thinned rows, there should be little further increase in curvature.

It appears that row-thinning does not result in sufficient sweep to degrade the value of red pine grown at this spacing and thinned at this stage of development. Since the crowns had already fully closed at thinning, there seems to be no reason why a taller stand would react differently, beyond the fact that curvature would develop higher up the stem. Finally, site probably has little effect on this matter since, for a given spacing, the rate of crown expansion is likely proportional to the rate of height growth.

\section{REFERENCES}

BUSGEN, M., and E. MUNCH, 1929. The structure and life of forest trees. 3rd Ed. Translated

by T. Thomson. Chapman and Hall, London.

SNEDECOR G,W. 1946. Sratistical methods, 4ch Ed. Iowa Stare College Press, Ames, Iown

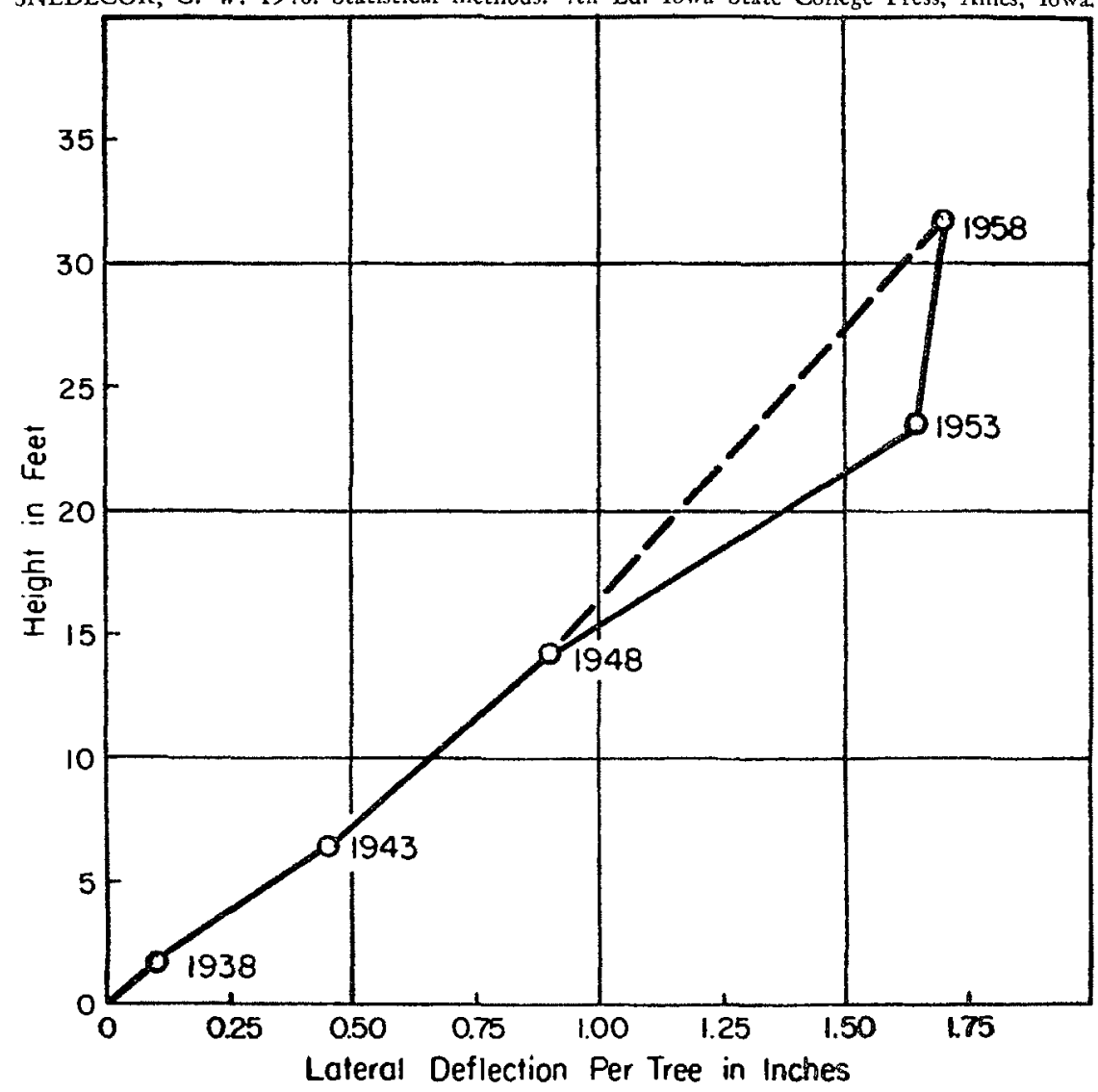

FIGURE 1 